\title{
Impact of Leadership Styles on the Organizational Commitment of Medical Practitioners: The Moderating Effects of Workplace Stress
}

\author{
Pubadi Govindasamy ${ }^{1}$, Nor Wahiza Abdul Wahat ${ }^{1}$, Siti Noormi Alias ${ }^{1}$, Khairuddin Idris ${ }^{1}$, Seyedali Ahrari ${ }^{1}$ \\ ${ }^{1}$ Faculty of Educational Studies, Universiti Putra Malaysia, Serdang, Selangor, Malaysia \\ Correspondence: Nor Wahiza Abdul Wahat, Faculty of Educational Studies, Universiti Putra Malaysia, 43400 \\ UPM Serdang, Selangor, Malaysia. Tel: 603-9769-8210. E-mail: wahiza@upm.edu.my
}

Received: September 3, 2021

Accepted: September 28, 2021 Online Published: October 15, 2021

doi:10.5539/ass.v17n11p133

URL: https://doi.org/10.5539/ass.v17n11p133

\begin{abstract}
The healthcare system is now facing several problems, which demands managers and leaders learning from various leadership styles and staff empowerment techniques to establish a work environment that supports medical practitioners' dedication to patients and their company. The present study aims to examine the leadership styles and organizational commitment of medical practitioners at the Melaka State Health Department [Jabatan Kesihatan Negeri Melaka (JKNM)], Malaysia, and the influence of workplace stress. In particular, this study explored the moderating effects of workplace stress on the association between leadership styles and organizational commitment among medical practitioners. The study used a quantitative approach based on the Social Exchange Theory by Homans and Lewin's Person-Environment Fit Model. The survey involved questionnaires distributed to obtain data from 309 medical practitioners. The data collected were analyzed using description means and hierarchical regression. The results revealed a significant correlation and moderating effect of workplace stress on leadership styles (i.e., Transformational Leadership, Transactional Leadership, and Laissez-Faire Leadership) and organizational commitment among JKNM medical practitioners. This paper also considered the theoretical and practical implications and made recommendations for future research.
\end{abstract}

Keywords: Workplace Stress, Moderating Effect, Leadership Styles, Organizational Commitment, Medical Practitioners, Jabatan Kesihatan Negeri Melaka (JKNM)

\section{Introduction}

Contemporary healthcare organizations in many developing countries are facing various challenges. These challenges include threats to the workforce, shifting customer preferences and requirements, budgetary restrictions, growing pressure for better access to treatment, legislation to strengthen patient-centered treatment, and the quality and safety standards of healthcare. Hence, effective leadership and administration is the key to optimizing efficient healthcare management (MacPhee et al., 2013). Leadership relates to the additional push by a leader to boost organizational performance, efficiency, and effectiveness. On the contrary, a weak leadership style refers to the lack of participation by the leader and restricts the organization's success, leadership satisfaction, and efficiency (Ebrahimi et al., 2017).

Kramer et al. (2010) stated that hospital and nursing managers have outstanding leadership styles in the medical profession, particularly in the area of transformative leadership, and their care managers implement a non-discriminatory system for their employees. Previous studies revealed that the quality of treatment declined due to a heavy workload (Duffield et al., 2014). Key steps were needed to eliminate inconsistencies between nursing managers and nurses because the overarching objective of exchanging daily priorities, language, and the general purpose of nursing managers is to establish well-equipped or qualified caregivers who provide quality services (Carlos et al., 2011).

Work-related stress has long been studied and seen as a common stress factor. Most researchers concluded that stress linked to workload has adverse effects on the employees' healthcare and safety (Edgar et al., 2017). The heavy workload of medical practitioners caused a decline in their work efficiency and healthcare (Horton et al., 2018). The above findings indicate a clear link between stress and health. Stress is a silent killer with significant effects on physical and psychological health. High stress is a major health risk factor (Yamaguchi et al., 2017). Research has shown that stress is a strong predictor affecting the physical and mental health of adults (Firoozabadi et al., 2018). Studies on physical health results showed that high job demands, limited 
decision-making latitude, and disparity in commitment are all connected to increased heart disease incidences (Yamaguchi et al., 2017). In addition, many employees considered leadership actions to have a direct impact on their well-being.

Leadership reinforcement has a positive effect on job efficiency and well-being. Leadership is critical to excellent performance because it organizes the business's use of people and other resources. A strong leader inspires employees and motivates individuals not only to improve their job performance but also their loyalty to the organization. Some concepts tamped down the impact of stress on illness (Nauman et al., 2019). Jyoti and Bhau (2016) stressed that previous studies examined leadership and health, but very few studies explored the moderating effects between workplace stress, health, leadership styles, and organizational commitment (Abbasi, 2018; Nielsen et al., 2019). Medical professionals play an important part in the healthcare system. They diagnose and treat physical and mental sickness, disease, and infection, as well as prescribing drugs and treatments and referring patients to other experts as needed. Work overload, long working hours, sleep deprivation, frequent exposure to emotionally charged situations, dealing with difficult patients, and disputes with other staff members all put them under a lot of stress (Hafiz et al., 2018). This necessitates managers empowering their medical practitioners to carry out their responsibilities by best practices. It also needs managers to demonstrate their dedication by creating a positive work atmosphere while still providing high-quality treatment and ensuring patient safety (Farokhzadian et al., 2018). This research, therefore, proposes to test whether stress in the workplace influences the relationship between leadership styles and organizational commitment.

It is vital for healthcare providers, employees, and organizations to evaluate workplace-related stress and its contributing factors among medical practitioners. Hence, the current study aims to examine the moderating interaction between the moderating effects of workplace stress, leadership styles, and organizational commitment among medical practitioners at the Melaka State Health Department [Jabatan Kesihatan Negeri Melaka (JKNM)].

\subsection{Literature Review}

Two theoretical perspectives formed the basis of this study - the Social Exchange Theory developed by Homans in the 1960s and the Person-Environment Fit model established by Lewin in the 1950s. The Social Exchange Theory (SET) refers to social, psychological, and sociological characteristics depicting stability and social shifts in negotiating exchanges amongst parties (Cropanzano et al., 2017). This theory claims that the relationships shared by humans are derived from the analysis of subjective behavioral cost-benefit, as well as by comparing the alternatives upon interaction. Harmeling et al. (2017) claimed that several factors, for example, power, conformity, status, leadership, and justice within social behavior are significant to elaborate costs between negative values and rewards (sense of acceptance, support, and companionship) that have positive values on a person. Generally, one calculates the wholesome value of the relationship by including rewards and excluding costs. Worth is a positive relationship, while costs are the negative results otherwise. In short, the value of a relationship is summarized by the equation "Worth = Rewards - Costs" (Cropanzano et al., 2017).

This causal link is crucial in assessing the characteristics and value of leadership. In this study, the inherent features of the SET model are the social exchange and stability of the relationship between parties, i.e., between the leader/employer and followers/employees (Um \& Yoo, 2018). Accordingly, the SET model explains the outcome on satisfaction and dependence of relationships by comparing "worth" valuation and the cost of contractual job requirements against job satisfaction and rewards. The equation suggests that the negotiation or comparative exchange of rewards and costs become pivotal variables in which positive or negative outcomes influence employee retention.

Meanwhile, the Person-Environment Fit model suggests that work stress occurs when employees perceive a difference between individual needs and whether the working environment meets employees' requirements (Ho \& Astakhova, 2018). The Demand-Control Support model (De Lange et al., 2003) states that stress depends on the level of job demands, the degree of control perceived to complete tasks, and the amount of help provided to employees. According to the Equity theory, work-related stress occurs when employees view their relationship with the organization as providing more professional value rather than earning incentives (Hobfoll \& Freedy, 2017).

The transactional stress and coping model shows that stress levels in the workplace rely on inner cognitive processes and how employees cognitively perceive work-related challenges. Nevertheless, the theory was never explicitly formulated to describe work stress in occupations involving health and social services to the public (Rippon, 2018). In this regard, occupational stress models provided more specific explanations on how stress factors unique to a particular occupation are enhanced (Fida et al., 2018). 
On the other hand, there were no clear or important connections between work-related stress and the form or frequency of behavior threatening medical practitioners (Fawzy \& Hamed, 2017). There may be other work-related factors affecting stress faced by health/social care employees who offer treatment to the public. Therefore, a thorough understanding of work-related processes is needed to assess the stress rates of medical practitioners and to avoid or de-escalate incidences of behavior that present challenges in their occupations.

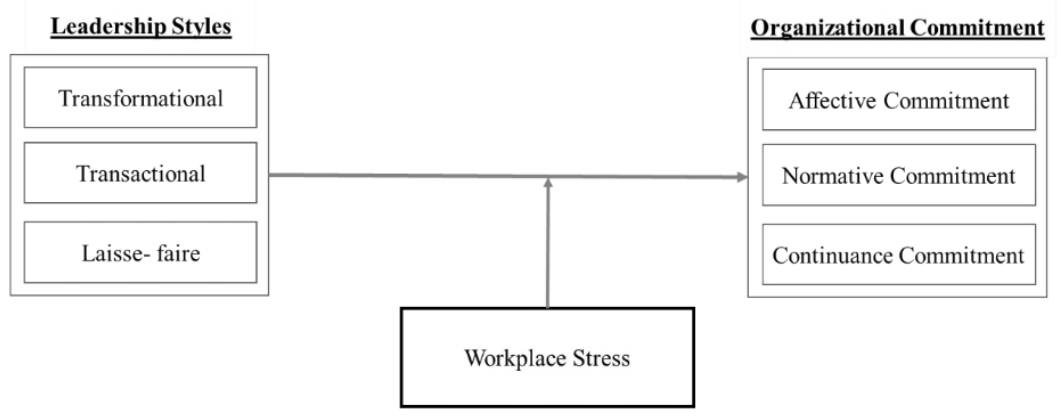

Figure 1. Research Framework

In this study, the literature review of these underpinning theories forms the diagrammatic view of the research framework for the hypothesis to be tested. The following hypothesis was developed to identify the relationship between leadership style, organizational commitment, and workplace stress: Workplace stress moderates the relationship between leadership style and organizational commitment.

\section{Methodology}

\subsection{Research Design}

There are two-time horizons for research, cross-sectional and longitudinal studies (Collis \& Hussey 2013). The cross-sectional analysis refers to research at a given moment of a particular phenomenon whereas a longitudinal study is an analysis in time observation of individuals or events (Saunders \& Lewis, 2012). For this research, the cross-sectional analysis explored the relationship between leadership, organizational commitment, and workplace stress among medical practitioners at the Melaka State Health Department [Jabatan Kesihatan Negeri Melaka (JKNM)]. The study employed a cross-sectional design because it is a form of observational study in medical and organizational research that analyses data from a population, or a representative subset, at a given point in time (Olsen \& George, 2004).

\subsection{Population and Sample}

The participants for this research consisted of medical practitioners (e.g medical doctors, dentists, and pharmacists) working at JKNM, Malaysia, and employed a non-probability purposive sampling technique. Purposive sampling is appropriate when a study defines a specific sample selection criterion (Cooper \& Schindler, 2014). This study used the estimation of sample size in Krejcie and Morgan's (1970) Sample Size Table. The present study involved 1,407 government medical practitioners in Melaka i.e., 1,050 medical doctors, 136 dentists, and 221 pharmacists (as of 31 December 2013). The given population used a sample size of 302. The selection of samples for this study was based on each category of medical practitioners like medical doctors, dentists, and pharmacists in Melaka and dispersed according to the working facilities.

\subsection{Measures}

Leadership Style. Bass (1995) created the multifactor leadership questionnaire as a tool for assessing leadership styles (MLQ). The leadership styles are discussed in this tool. This instrument was chosen because it assesses leadership across three core aspects (Yukl 2002) that can be used to create leadership profiles; it has been reliability tested and validated in other countries, and it has been used in other countries (e.g., Ekvall \& Arvonen 1994). This independent variable contained three leadership style variables: Transformational Leadership, Transactional Leadership, and Laissez-Faire Leadership. Overall, these variables made up 36 questions and were categorized as closed-ended and measured by an interval scale of the 5-point Likert Scale.

Organizational Commitment. The Organizational Commitment Questionnaire (QCQ), developed by Mowday et al. (1979), was used to assess organizational commitment. Involvement was measured using two scales. One was a graphic scale that asked respondents to rate their level of involvement in their current job. The other asks 
respondents to rate their level of involvement in their work on a 5-point scale (as opposed to involvement with their families or with leisure activities). A total of 8 questions were developed to measure each element of Affective, Normative, and Continuance commitments. All 24 questions were categorized as closed-ended and measured by an interval scale of the 5-point Likert scale that represented the level of agreement to a statement i.e. 'strongly disagree, disagree, neither agree nor disagree, agree, and strongly agree'.

Workplace Stress. The moderating variable of this study measured by The Stress Questionnaire identified the stress factors in the respondents' work and their method or strategies of coping with the said stress. Based on the North-Western National Life (NWNL) Workplace Stress Test in Reece and Brandt's (1999) Classroom Activities Manual (1999), all 29 questions on employer support and training, work conditions and job design, and physical environment were categorized as closed-ended and measured by an interval scale of the 5-point Likert Scale.

\subsection{Validity of the Questionnaire}

Validity means the extent to which a research concept is accurately established by testing or measuring data collection, or the degree it is free from any systemic error (Hair et al., 2010). The questionnaire in this study used the following methods of assessment: face validity, content validity, and construct validity.

\subsubsection{Face Validity}

Face validity measures the scope of the instrument (Sekaran \& Bougie, 2016). Experts in the field or area must verify what the research instrument is supposed to assess. Five experts confirmed the validity of the survey method in this study. Three experts were medical practitioners from Melaka, (a medical doctor, dentist, and pharmacist), and two were academics from Universiti Putra Malaysia.

\subsubsection{Content Validity}

Content validity is the extent to which the scale items correctly represent the entire scope of the measured contents (Malhotra, 2004). A thorough review of the research literature is required to determine the validity of the material. Accordingly, this study carried out a pilot test to ensure the adequacy of the survey instrument used to assess the validity of the material (Saunders \& Lewis, 2012). This paper considered recommendations from experts on the structure and organization of the instrument to improve the consistency of the survey questionnaire.

\subsubsection{Construct Validity}

Construct validity indicates how well the instrument used in the analysis tests the theoretical definition and structure based on two aspects: convergent validity and discriminant validity (Hair et al., 2010). Convergent validity is the degree to which the scale positively correlates with other construction indicators (Saunders \& Lewis, 2012). This study used the Factor Analysis to calculate convergent validity, whereas test discriminant validity used the Pearson's correlation test.

\subsubsection{Reliability of the Questionnaire}

Reliability is an assessment of how accurately a measuring instrument measures the concept against a variable's multiple measurements (Hair et al., 2010). It shows the consistency of effects for repeated measurements taken in the unit over time, population, and different elements. In other words, it indicates the reliability and precision of the measured length. This study used Cronbach alpha to evaluate the reliability of the questionnaire and the internal precision of the elements for one dimension. The Cronbach Alpha coefficient is the most widely used inter-item coherence measure in a multipoint measurement scale (Saunders \& Lewis, 2012; Hair et al., 2010). Since the Likert interval scale measured the independent and dependent variables in the sample, Cronbach's alpha was deemed adequate.

\subsection{Pilot Testing}

Before the data collection, a pilot test conducted on 37 medical practitioners assessed the accuracy and reliability of the survey questionnaire. Pilot analysis refers to screening a particular group of interviewees to strengthen the questionnaire by finding and eliminating possible issues and vulnerabilities (Sekaran \& Bougie, 2016; Cooper \& Schindler, 2014). Based on the feedback and recommendations of the respondents, changes were made to the questionnaire.

\subsection{Data Collection Method}

There are two kinds of questionnaires that are relevant to data collection, namely, self-administered and interviewer questionnaires (Saunders \& Lewis, 2012). Due to the large sample size, budget, and time constraints, this study adopted a self-administered questionnaire to collect information from the respondents (Sekaran \& 
Bougie, 2016). To achieve 302 responses, the questionnaires were personally distributed to 437 possible respondents at eight locations based on healthcare facilities at JKNM as shown in Table 1 below.

Table 1. Geographical Distribution of Questionnaire

\begin{tabular}{|c|c|c|c|c|}
\hline No & Location & Medical Doctor & Dentist & Pharmacist \\
\hline 1 & Melaka Hospital & 772 & & 99 \\
\hline 2 & Alor Gajah Hospital & 21 & & 12 \\
\hline 3 & Jasin Hospital & 19 & & 7 \\
\hline 4 & Melaka Tengah District Health Office & 109 & & 40 \\
\hline 5 & Alor Gajah District Health Office & 62 & & 17 \\
\hline 6 & Jasin District Health Office & 44 & & 18 \\
\hline 7 & Dentist \& Pharmacy JKNM HQ & - & 132 & \\
\hline \multirow[t]{3}{*}{8} & JKNM HQ & 23 & 4 & 28 \\
\hline & Total medical practitioners & 1050 & 136 & 221 \\
\hline & Total Sample needed & 224 & 30 & 48 \\
\hline
\end{tabular}

\subsection{Data Analysis Method}

This study used the Statistical Package for Social Sciences (SPSS) software version 23 to analyze the data collected. According to Sekaran and Bougie (2016), the three goals in data analysis are: (1) a feel for the data obtained; (2) data quality testing; and (3) analysis hypothesis testing. To achieve these goals and the aims of this study, the following analysis methods were used to test the research objectives and hypothesis: cross-sectional analysis (descriptive analysis and factor analysis), reliability analysis (correlation analysis), and regression analysis.

\section{Findings and Analysis}

\subsection{Response Rate}

The questionnaire's response rates were calculated by calculating the net communication replies. The target population is 1,407 medical practitioners and 437 questionnaires were distributed. The total response received is 309 , in which the return rate is equivalent to 70.7 percent. Based on recommendations from Aguinis et al. (2018) and Hair et al. (2013), this quantity is adequate for multivariate analysis and reporting with a response rate of at least 30 percent. The raw data input was then screened, cleaned, and checked to ensure accuracy (DeSimone et al., 2015).

\subsection{Test of Normality}

Three statistical tests including descriptive statistics, factor analysis, and regression analysis were implemented using parametric statistics to the homogeneous and continuous sample data (Ali \& Bhaskar, 2016). Table 2 shows the normally distributed Mean and Standard Deviation values of the seven variables of this study.

Table 2. Test of Normality

\begin{tabular}{ccccccc}
\hline Variables & Mean & Standard Deviation & Skewness & Kurtosis & Shapiro-Wilk & Sig \\
\hline Transformational & 3.59 & .594 & -.472 & .427 & .979 & .002 \\
Transactional & 3.44 & .586 & -.299 & -.459 & .978 & .001 \\
Laissez-faire & 1.85 & .835 & -.259 & -.595 & .971 & .000 \\
Affective & 3.27 & .771 & -.669 & .957 & .952 & .000 \\
Normative & 3.84 & .727 & -.648 & .584 & .961 & .000 \\
Continuance & 17.06 & .694 & -.499 & .268 & .971 & .000 \\
Workplace Stress & 19.00 & .605 & -.774 & .206 & .940 & .000 \\
\hline
\end{tabular}

The Skewness and Kurtosis found in the range of -1.96 to +1.96 (Doane \& Seward, 2011) rejected the extremely skewed or Kurtoic data issue that inflated the bootstrapped standard error (Chernick, 2011). Furthermore, the Kolmogorov-Smirnov and Shapiro-Wilk tests examined the normality of the distribution of data. The significant value of the Shapiro-Wilk test greater $(p>.05)$ indicates data normality. In Table 3, the Shapiro-Wilk test shows that the data obtained were distributed normally (Hanusz \& Tarasińska, 2015; Oppong \& Agbedra, 2016). As a result, the study proceeded to adopt parametric procedures that assume normality. 


\subsection{Multicollinearity}

A tolerance score of 0.2 or greater, a VIF value of 10 or higher, and a Condition Index (CI) value higher than 30 (Hair et al., 2011) indicate the presence of multicollinearity. The independent variables tolerance and VIF values in Table 3 indicated all tolerance values higher than 0.2, VIF values below 10, and CI below 30 that suggested multicollinearity is not a threat to the results.

Table 3. Test of Collinearity

\begin{tabular}{cccc}
\hline Independent Variables & Tolerance & VIF & Condition Index \\
\hline Transformational & .505 & 1.979 & 10.772 \\
Transactional & .314 & 3.181 & 16.006 \\
Laisse-Faire & .398 & 2.515 & 20.129 \\
Affective & .571 & 1.751 & 22.385 \\
Normative & .342 & 2.926 & 25.125 \\
Continuance & .386 & 2.590 & 29.755 \\
Workplace Stress & .613 & 1.630 & 33.958
\end{tabular}

Note. VIF = Variance Inflation Factor

\subsection{Demographic Profile of Respondents}

In total, there were 309 respondents. Table 4 displays a summary of the demographic profiles of the respondents.

Table 4. Demographic Profile $(n=309)$

\begin{tabular}{|c|c|c|}
\hline Profile & Frequency & $\%$ \\
\hline \multicolumn{3}{|l|}{ Gender } \\
\hline Male & 82 & 26.5 \\
\hline Female & 227 & 73.5 \\
\hline \multicolumn{3}{|l|}{ Age } \\
\hline Below 30 years old & 216 & 69.9 \\
\hline 30 - 45 years old & 81 & 26.2 \\
\hline More than 45 years old & 12 & 3.9 \\
\hline \multicolumn{3}{|l|}{ Race } \\
\hline Malay & 170 & 55.0 \\
\hline Chinese & 91 & 29.4 \\
\hline Indian & 43 & 13.9 \\
\hline Others & 5 & 1.6 \\
\hline \multicolumn{3}{|l|}{ Marital Status } \\
\hline Not married & 167 & 54.0 \\
\hline Married & 141 & 45.6 \\
\hline Widow/Widower & 1 & 0.3 \\
\hline \multicolumn{3}{|l|}{ Highest Education Level } \\
\hline Graduate & 277 & 89.6 \\
\hline Post Graduate & 32 & 10.4 \\
\hline \multicolumn{3}{|l|}{ Profession } \\
\hline Medical doctor & 204 & 66.0 \\
\hline Dentist & 50 & 16.2 \\
\hline Pharmacist & 55 & 17.8 \\
\hline \multicolumn{3}{|c|}{ Length of Service in Public Sector } \\
\hline Less than 5 years & 214 & 69.3 \\
\hline 5-10 years & 63 & 20.4 \\
\hline More than 10 years & 32 & 10.4 \\
\hline \multicolumn{3}{|l|}{ Length of Service at JKNM } \\
\hline Less than 5 years & 252 & 81.6 \\
\hline 5-10 years & 39 & 12.6 \\
\hline More than 10 years & 18 & 5.8 \\
\hline
\end{tabular}


Managerial Grade

$\begin{array}{lcc}29 & 1 & 0.3 \\ 32 & 6 & 1.9 \\ 38 & 3 & 1.0 \\ 40 & 1 & 0.3 \\ 41 & 166 & 53.7 \\ 44 & 67 & 21.7 \\ 48 & 41 & 13.3 \\ 52 & 11 & 3.6 \\ 54 & 13 & 4.2\end{array}$

As seen in Table 4 above, out of 309 respondents, 82 respondents (26.5\%) were male, and 227 were female (73.5\%). In 2018, the high number of female respondents commensurate gender diversity in the medical workforce as reported by the Ministry of Health (MOH) and World Health Organization (WHO) (source: Human Resources for Health Country Profiles - Malaysia, World Health Organization, 2018). In terms of age distribution, $69.9 \%$ of the respondents were below 30 years old, $26.2 \%$ of respondents were between 30 to 45 years old, and the remaining $3.9 \%$ of respondents were more than 45 years old. The wide age range indicates a diverse sample distribution. Two-thirds of the respondents were below 30 years old. Almost $70 \%$ of respondents from this age group are junior medical practitioners who joined the public health services after their undergraduate studies to obtain full accreditation and professional membership from the professional regulatory bodies. This age group of medical practitioners is the largest group that usually quits public health services after receiving accreditation.

The majority of the respondents were Malay medical practitioners (55\%), followed by Chinese respondents (29.4\%), Indian (13.9\%), and $1.6 \%$ of respondents categorized as others. As for marital status, 54\% of respondents were not married, $45.7 \%$ were married, and only $0.3 \%$ of respondents were widowed. On the highest education level, $89.6 \%$ of respondents graduated with a bachelor's degree, and the remaining (10.4\%) respondents were postgraduate degree holders.

In terms of the profession, $66 \%$ of the respondents were medical doctors, $16.2 \%$ were dentists, and the remaining $17.8 \%$ were pharmacists. Because of the length of service in the public sector, $69.3 \%$ of respondents served less than five years, $20.4 \%$ worked between five to ten years, and the remaining $10.4 \%$ served more than ten years. Conversely, the length of service at JKNM showed that most of the respondents $(81.6 \%)$ worked less than five years, $12.6 \%$ worked between five to ten years, and 5.8\% of respondents served more than ten years at JKNM. Therefore, the findings of this study reflected the opinion of considerably new medical practitioners at JKNM.

Finally, the survey consisted of the managerial grade 29 to grade 54 . The survey showed that $0.3 \%$ of respondents were grade $29,1.9 \%$ respondents were grade $32,1 \%$ were grade $38,0.3 \%$ of respondents were grade $40,53.7 \%$ were grade $41,21.7 \%$ respondents were grade $44,13.3 \%$ grade $48,3.6 \%$ grade 52 and, $4.2 \%$ of respondents were grade 54 .

\subsection{Goodness of Measure}

In this study, the validity and reliability tests analyzed the goodness of measures. The subsequent sections discuss the results.

\subsubsection{Factor Analysis}

The Principal Component Analysis (PCA) was selected to extract the relevant factors (Nguyen \& Holmes, 2019). According to Hair et al. (2013), loading objects above 0.50 are considered crucial. Hence, the results were derived from the Kaiser-Meyer-Olkin (KMO), Sampling Adequacy Measurements, and Bartlett Sphere Tests in interpreting the rotated component matrix. The KMO Kaiser statistics (1974) considers 0.5 to 0.7 as mediocre, with 0.7 to 0.8 as good values, 0.8 to 0.9 as high values, and 0.9 as superior values. The results of the KMO test for sampling adequacy shown in Table 5 indicated the value of 0.921 within the range of large samples. The sample size is therefore ideal for the study of the factor.

As shown in Table 6, Bartlett's Test of Sphericity is significant at $p<.001$. This significance level is small enough to reject the null hypothesis. Hence, the correlation matrix is not an identity matrix. When the abovementioned statistical requirements are satisfied, the analysis construed factors with an eigenvalue greater than 1 . 
Table 5. KMO and Bartlett's Test of Sphericity

\begin{tabular}{lll}
\hline Kaiser-Meyer-Olkin Measure of Sampling Adequacy. & & .921 \\
\hline & Approx. Chi-Square & 22180.376 \\
Bartlett's Test of Sphericity & df & 2016 \\
& Sig. & .000 \\
\hline
\end{tabular}

\subsubsection{Total Variance Explained}

The study searched for variables with values greater than or equal to 1 using the criterion of Kaiser. The first ten components of Table 6 had equivalent values of more than or equal to 1 and accounted for $77.16 \%$ of the variations: component 1 represented 38.86\%, component 2 accounted for $11.06 \%$, and component 3 accounted for $7.41 \%$ of the variation. Thus, a maximum of 10 components was extracted from the combined data set, based on the analysis explained in the total variance.

Table 6. Total Variance Explained

\begin{tabular}{ccccccc}
\hline \multirow{2}{*}{ Components } & \multicolumn{3}{c}{ Initial Eigenvalues } & \multicolumn{3}{c}{ Rotation Sums of Squared Loadings } \\
\cline { 2 - 6 } & Total & \% of Variance & Cumulative \% & Total & \% of Variance & Cumulative \% \\
\hline 2 & 24.872 & 38.862 & 38.862 & 11.781 & 18.408 & 18.408 \\
3 & 7.077 & 11.057 & 49.919 & 6.917 & 10.807 & 29.216 \\
4 & 4.746 & 7.415 & 57.335 & 6.312 & 9.863 & 39.079 \\
5 & 2.574 & 4.021 & 61.356 & 5.540 & 8.657 & 47.735 \\
6 & 2.229 & 3.482 & 64.838 & 3.972 & 6.206 & 53.941 \\
7 & 1.892 & 2.956 & 67.795 & 3.843 & 6.004 & 59.945 \\
8 & 1.805 & 2.820 & 70.614 & 3.212 & 5.019 & 64.964 \\
9 & 1.650 & 2.578 & 73.193 & 3.188 & 4.982 & 69.946 \\
10 & 1.341 & 2.096 & 75.289 & 2.754 & 4.303 & 74.249 \\
11 & 1.200 & 1.875 & 77.164 & 1.866 & 2.915 & 77.164 \\
12 & .997 & 1.558 & 78.722 & & & \\
88 & .935 & 1.461 & .006 & 80.183 & & \\
\end{tabular}

Note. Extraction Method: Principal Component Analysis.

\subsubsection{Reliability Analysis}

In this study, the alpha $(\alpha)$ coefficient of Cronbach estimated the internal consistency aspect of measuring instrument reliability by testing the seven key variables as illustrated in Table 7. The rule of thumb: $\alpha$ is good above the value of $0.9 ; \alpha$ is excellent over the value of $0.8 ; \alpha$ is good over the value of $0.7 ; \alpha$ is acceptable over the value of 0.6 , and $\alpha$ above and below 0.5 is uncommon. An alpha coefficient of Cronbach value closer to 1.0leads to the higher internal consistency of the items in the scale. The reliability coefficients were well over 0.754 for all the measuring elements that showed the dimensions generated in this study were reliable in terms of internal consistency.

Table 7. Summary of Reliability Analysis

\begin{tabular}{ccc}
\hline Variable & No. of Items & $\alpha$ \\
\hline Transformational & 8 & 0.754 \\
Transactional & 4 & 0.935 \\
Laisse-Faire & 4 & 0.844 \\
Affective & 8 & 0.833 \\
Normative & 8 & 0.863 \\
Continuance & 8 & 0.820 \\
Workplace Stress & 29 & 0.868 \\
\hline
\end{tabular}




\section{Discussion on Research Findings}

The findings and main effects of workplace stress on leadership styles and its interaction with organizational commitment are discussed below.

\subsection{Transformational Leadership}

The hierarchical regression analysis tested the moderating effect of workplace stress on the correlation between leadership styles and organizational commitment among JKNM medical practitioners. The workplace stress variable was multiplied with the dummy-coded categorical variable as low, medium, and high. The three main effects and the interaction term were used in hierarchical regression to predict the organizational commitment among JKNM medical practitioners.

Table 8. Moderating effect of transformational leadership style and workplace stress and the interaction on organizational commitment

\begin{tabular}{|c|c|c|c|c|c|c|}
\hline & \multirow{2}{*}{ Model } & \multicolumn{2}{|c|}{ Unstandardized Coefficients } & \multirow{2}{*}{$\begin{array}{c}\text { Standardized Coefficients } \\
\text { Beta }\end{array}$} & \multirow{2}{*}{$\mathrm{t}$} & \multirow{2}{*}{ Sig. } \\
\hline & & $\mathrm{B}$ & Std. Error & & & \\
\hline \multirow{2}{*}{1} & (Constant) & 1.681 & .186 & & 9.051 & .000 \\
\hline & Transformational Leadership & .408 & .051 & .415 & 8.003 & .000 \\
\hline \multirow{3}{*}{2} & $($ Constant $)$ & .804 & .292 & & 2.756 & .006 \\
\hline & Transformational Leadership & .383 & .050 & .391 & 7.628 & .000 \\
\hline & Workplace Stress & .307 & .080 & .197 & 3.838 & .000 \\
\hline \multirow{4}{*}{3} & (Constant) & 3.287 & 1.011 & & 3.250 & .001 \\
\hline & Transformational Leadership & -.351 & .291 & -.358 & -1.207 & .228 \\
\hline & Workplace Stress & -.454 & .308 & -.290 & -1.476 & .141 \\
\hline & laissez*stress & .225 & .088 & .952 & 2.562 & .011 \\
\hline
\end{tabular}

Dependent Variable: Organizational Commitment

Based on Table 8, the first model shows the main effect for the transformational leadership style of $(\beta=.415, p$ $<.001$ ), which was positively associated with organizational commitment. In the second model, workplace stress was found to have a significantly positive prediction on organizational commitment $(\beta=.197, p<.001)$. In this study, this is a new finding. Normally, employees who reported more workplace stress tend to have a negative organizational commitment (Cropanzano \& Mitchell, 2005). In the third model, the result showed that the interaction harms workplace stress $(\beta=-.290, p>.001-.290, p>.010)$, and signified that workplace stress influenced the correlation between transformational leadership style and organizational commitment. However, this effect was qualified by the significant interaction $(\beta=.952, p<.010)$, which was graphed using the techniques recommended by Aiken et al. (1991) in Figure 2.

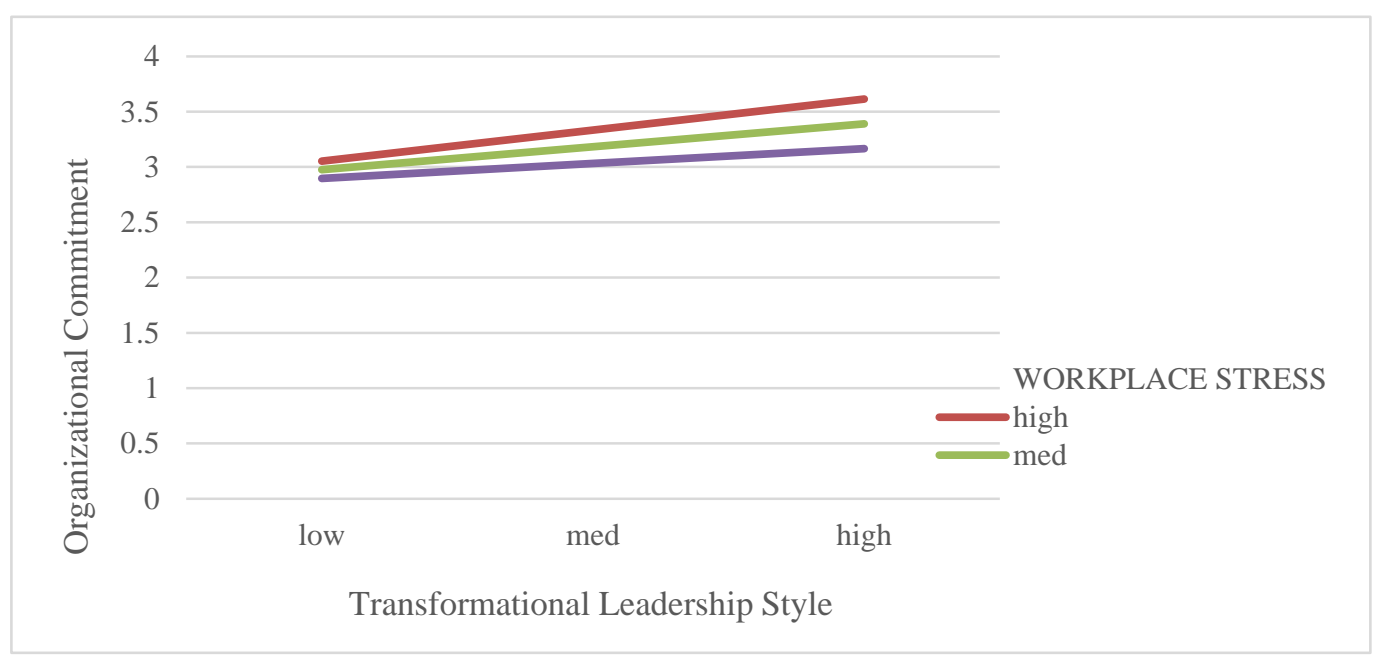

Figure 2. Transformational Leadership Style

Figure 2 shows that under low, medium, and high levels of workplace stress, transformational leadership showed an increase in organizational commitment. 
Based on Figure 2, there is a modest spread or fan effect. The fan pattern occurs at either the right or left side, and the general trend of the lines can be either negative or positive in slope. The average transformational leadership style-to-organizational commitment relationship with the moderating effect of workplace stress line is a positive slope. This result confirmed that the transformational leadership style among JKNM medical practitioners is related to them working under significant workplace stress.

\subsection{Transactional Leadership}

Table 9. Moderating effect of transactional leadership style and workplace stress and the interaction on organizational commitment

\begin{tabular}{|c|c|c|c|c|c|c|}
\hline & \multirow{2}{*}{ Model } & \multicolumn{2}{|c|}{ Unstandardized Coefficients } & \multirow{2}{*}{$\begin{array}{c}\text { Standardized Coefficients } \\
\text { Beta }\end{array}$} & \multirow{2}{*}{$\mathrm{t}$} & \multirow{2}{*}{ Sig. } \\
\hline & & $\mathrm{B}$ & Std. Error & & & \\
\hline \multirow{2}{*}{1} & (Constant) & 1.699 & .180 & & 9.424 & .000 \\
\hline & Transactional Leadership & .420 & .052 & .422 & 8.149 & .000 \\
\hline \multirow{3}{*}{2} & (Constant) & .904 & .285 & & 3.167 & .002 \\
\hline & Transactional Leadership & .391 & .051 & .392 & 7.619 & .000 \\
\hline & Workplace Stress & .286 & .081 & .183 & 3.547 & .000 \\
\hline \multirow{4}{*}{3} & (Constant) & 4.350 & .996 & & 4.367 & .000 \\
\hline & Transactional Leadership & -.677 & .300 & -.680 & -2.254 & .025 \\
\hline & Workplace Stress & -.772 & .304 & -.493 & -2.541 & .012 \\
\hline & Laissez-Stress & .327 & .091 & 1.369 & 3.605 & .000 \\
\hline
\end{tabular}

Note. Dependent Variable: Organizational Commitment

In view of Table 9 , the first model shows the main effect for transactional leadership style of $(\beta=.422, p<.001)$. It was positively associated with organizational commitment. In the second model, workplace stress was found to significantly or positively predict organizational commitment $(\beta=.183, p<.001)$. In this study, this is a new finding. Normally, employees who reported more workplace stress tend to have a negative organizational commitment (Cropanzano \& Mitchell, 2005) and the third model findings proved to be significant. However, a significant negative effect of workplace stress $(\beta=-.493, p>.010)$ signified that workplace stress influenced the correlation between transactional leadership style and organizational commitment. In Figure 3 this effect was qualified by the significant interaction $(\beta=1.369, p<.001)$ and graphed using the techniques recommended by Aiken et al. (1991).

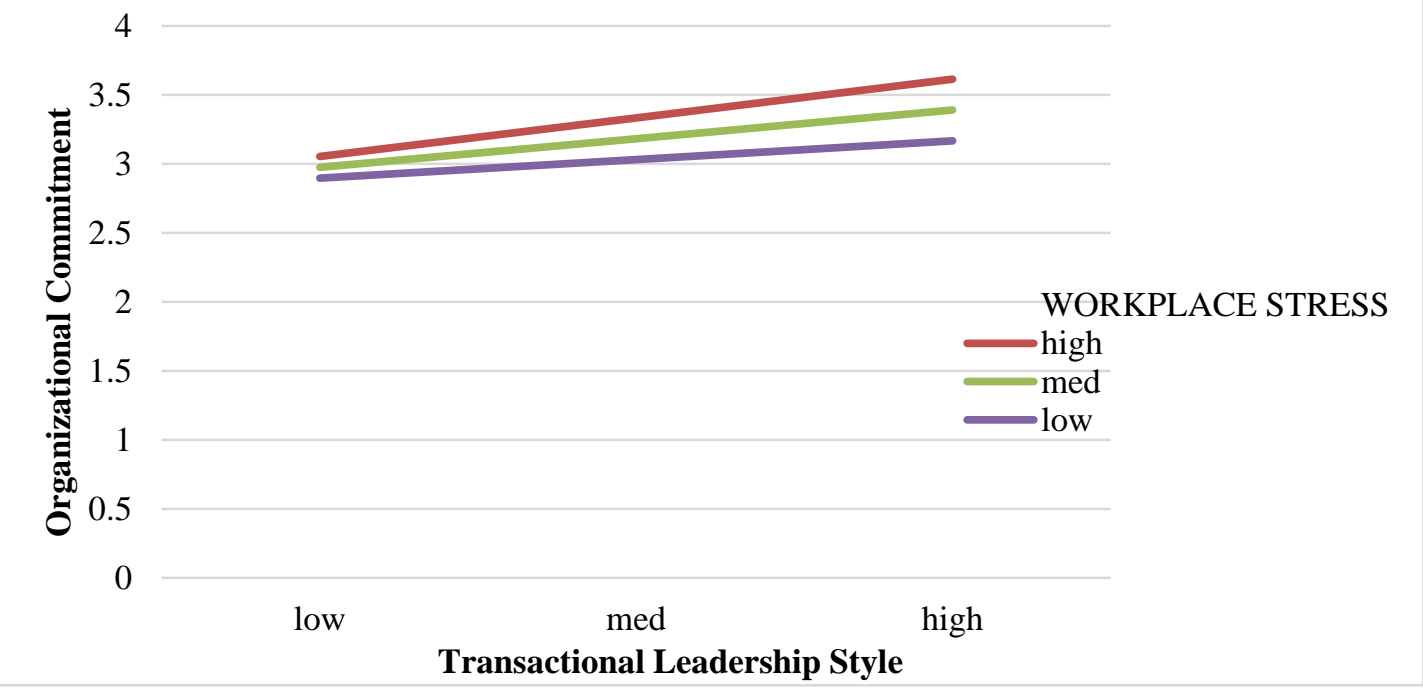

Figure 3. Transactional Leadership Style

Figure 3 shows that under low, medium, and high levels of workplace stress, transactional leadership showed an increase in organizational commitment.

As shown in Figure 3, there is a modest spread or fan effect. The fan pattern occurs at either the right or left side, 
and the general trend of the lines can be either negative or positive in slope. The average transactional leadership style-to-organizational commitment relationship with the moderating effect of the workplace stress line is a positive slope. This result confirmed the transactional leadership style among JKNM medical practitioners increased their organizational commitment even though they are under significant workplace stress.

\subsection{Laissez-Faire Leadership}

Table 10. Moderating Effect of Laissez-Faire Leadership Style and Workplace Stress and the Interaction on Organizational Commitment

\begin{tabular}{|c|c|c|c|c|c|c|}
\hline & \multirow{2}{*}{ Model } & \multicolumn{2}{|c|}{ Unstandardized Coefficients } & \multirow{2}{*}{$\begin{array}{c}\text { Standardized Coefficients } \\
\text { Beta }\end{array}$} & \multirow{2}{*}{$\mathrm{t}$} & \multirow{2}{*}{ Sig. } \\
\hline & & $\mathrm{B}$ & Std. Error & & & \\
\hline \multirow{2}{*}{1} & (Constant) & 3.178 & .081 & & 39.234 & .000 \\
\hline & Laissez Faire & -.017 & .040 & -.024 & -.426 & .671 \\
\hline \multirow{3}{*}{2} & (Constant) & 1.950 & .273 & & 7.147 & .000 \\
\hline & Laissez Faire & -.062 & .040 & -.089 & -1.564 & .119 \\
\hline & Workplac Stress & .418 & .089 & .267 & 4.702 & .000 \\
\hline \multirow{4}{*}{3} & (Constant) & 4.709 & .620 & & 7.601 & .000 \\
\hline & Laissez Faire & -1.392 & .273 & -1.993 & -5.098 & .000 \\
\hline & Workplace Stress & -.435 & .194 & -.278 & -2.247 & .025 \\
\hline & laissexstss & .404 & .082 & 2.120 & 4.919 & .000 \\
\hline
\end{tabular}

Dependent Variable: Organizational Commitment

Based on Table 10, the first model shows the main effect for the Laissez-Faire leadership style and the findings show a negative outcome $(\beta=-.024, p>.010)$. It can be concluded that the Laissez-Faire leadership style was not significantly associated with organizational commitment. Meanwhile, in the second model, workplace stress was found to be a significant positive predictor of organizational commitment $(\beta=.267, p<.001)$. In this study, this is a new finding (Cropanzano \& Mitchell, 2005). Normally, employees who reported more workplace stress tend to have negative organizational commitment. In the third model, the interaction term proved to be significant with a negative main effect of workplace stress $(\beta=-.278, p>.010)$ and signified that workplace stress influenced the correlation between Laissez-Faire leadership style and organizational commitment. This effect was qualified by the significant interaction in the third model $(\beta=2.120, p<.001)$ and illustrated in Figure 4 using the techniques recommended by Aiken et al. (1991).

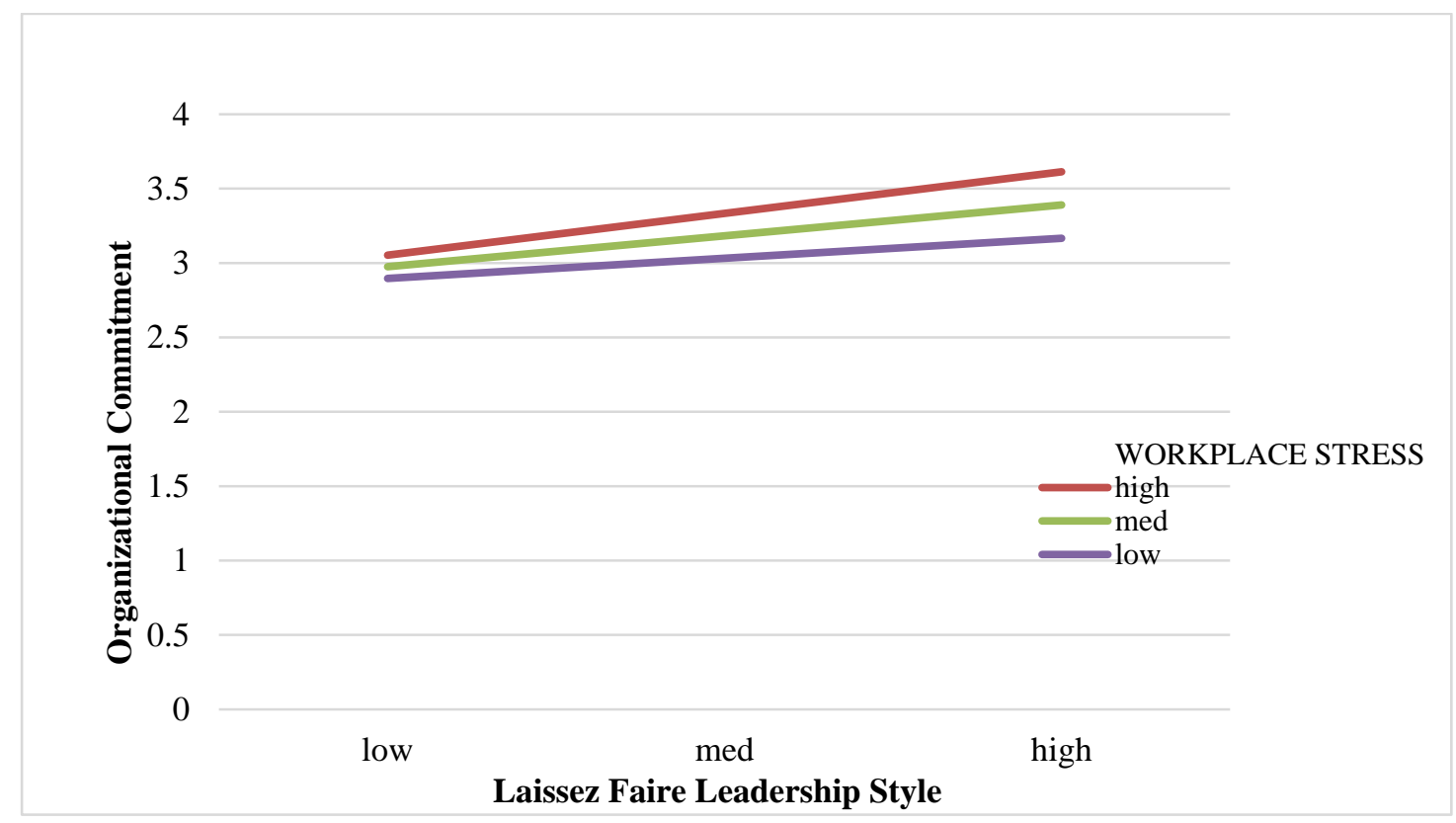

Figure 4. Laissez Faire Leadership Style 
Figure 4 illustrates that under low, medium, and high levels of workplace stress, Laissez-Faire leadership showed an increase in organizational commitment.

As shown in Figure 4, there is a modest spread or fan effect. The fan pattern occurs at either the right or left side, and the general trend of the lines can be either negative or positive in slope. The average Laissez-Faire leadership style to organizational commitment relationship with the moderating effect of workplace stress line is a positive slope. This result confirmed that the Laissez-Faire leadership style among JKNM medical practitioners increased organizational commitment even though they are under significant workplace stress.

As for the research question, it can be concluded that in the entire leadership situation, the workplace stress factor is a moderating variable positively correlated with organizational commitment. In this study, this is a new finding. Normally, employees who reported more workplace stress tend to have a negative organizational commitment (Cropanzano \& Mitchell, 2005). The main determinant to decide commitment in any set-up was the leaders and leadership styles. Organizational commitment and leadership style always goes along in a parallel dimension based on negotiated exchanges of effort and reward between leaders and followers (Cropanzano \& Mitchell, 2005), as explained through the application of the Social Exchange Theory introduced by George Homans in the 1960s.

The Social Exchange Theory claims that relationships shared by humans are based on the analysis of subjective behavioral cost-benefit, and comparing the alternatives upon interaction. Homans claimed that several features, for example, power, conformity, status, leadership, and social justice, are significant to elaborate costs with negative values and rewards (sense of acceptance, support, and companionship) that have positive values on a person. Generally, one calculates the wholesome value of the relationship by including rewards and excluding costs. Worth is a positive relationship, while costs are the negative results otherwise. In short, the value of a relationship is summarized by the equation "Worth = Rewards - Costs" (Cropanzano \& Mitchell, 2005).

This causal link is crucial in assessing the characteristics and value of leadership inherent in the Social Exchange Theory. The social exchange and stability of a relationship is a process of negotiated exchanges between parties and in this study between the leader/employer and followers/employees. Valuation of worth against the cost of contractual job requirements compared with job satisfaction and rewards based on the Social Exchange Theory explains outcome satisfaction and dependence of relationships (Emerson, 1976). In an employment relationship, the worth equation becomes "Outcome = Rewards - Costs" (Cropanzano \& Mitchell, 2005). This equation suggests that the negotiation or comparative exchange of rewards and costs become pivotal variables in which positive or negative outcomes influence employee retention.

\section{Conclusion and Recommendations}

The current study examined the moderating interaction of workplace stress between leadership styles and organizational commitment among JKNM medical practitioners. The items investigated in this research identified whether employer support and training, work conditions and job design, and physical environment have significant interaction between leadership styles and organizational commitment. The research findings concluded that in all leadership situations, the workplace stress factor is a moderating variable positively correlated with organizational commitment.

In summary, this study confirmed the medical profession as a noble profession with dedicated JKNM medical practitioners. In line with the notion of a noble calling, medical practitioners place importance on self-satisfaction rather than motivation in terms of monetary rewards. As a service-based industry, demographics such as gender and race also influenced the medical profession. The findings in this study concluded that leadership styles contribute significantly and play an important role in nurturing organizational commitment among medical practitioners at the Melaka State Health Department despite the presence of workplace stress. As a result of its collectivist society, which has a stronger preference for hierarchical relationships in terms of power, conformity, status, leadership, and justice within social behavior as explained by Social Exchange Theory, the above findings suggest that leadership styles are critical to the organizational commitment of medical practitioners in the Malaysian context (Sim al. 2004). In addition, the findings of this study show that there is a clear correlation between leadership styles and organizational commitment, which is moderated by workplace stress, that is connected to person-environment fit. This indicates that leadership styles should be focused on increasing total person-environment fit, which will lead to increased organizational commitment.At last, a medical practitioner should strive to improve their leadership styles and organisational commitment.

\section{Implications}

This study contributes to the growing body of knowledge specifically related to the leadership styles and 
organizational commitment among JKNM medical practitioners. Given the theoretical model contribution, the empirical results explained how medical practitioners should think critically about what, how, and why they must address leadership styles and organizational commitment. In other words, the theoretical model emphasized and promoted "reflection-on-action" of leadership styles and organizational commitment in the medical profession. Similarly, the theoretical model's empirical finding revealed that medical practitioners must understand the ability of public health organizations to build and maximize sustainable medical practitioners that bring effective changes through leadership styles and organizational commitment. Finally, healthcare leaders must pay attention not just to their leadership styles, but also to whether or not they are targeted at enhancing the fit between medical practitioners and their work environments.It is critical that policymakers consider the problems that medical practitioners face at the implementation level when establishing the leadership environment in order to provide chances to entrench leadership styles and organisational commitment in the healthcare sector.

\section{Limitations and Recommendations}

The main limitation concerned the results of this study. Firstly, medical practitioners employed as respondents participated in a questionnaire study and a semi-structured interview. Therefore, the sample could be influenced by the medical practitioners' professional experience and knowledge. Secondly, the statistical analysis only provided numerical relations in the quantitative phase. The understanding of these figures depends on the researcher's subjective evaluation. However, the results comply with other theories and studies, which enhanced confidence in the findings. Future research using a pure quality ethnography method is recommended for a better understanding of this study.

\section{References}

Abbasi, S. G. (2018). Leadership styles: Moderating impact on job stress and health. Journal of Human Resources Management Research, 2018, 1-11. https://doi.org/10.5171/2018.322892

Aguinis, H., Ramani, R. S., \& Alabduljader, N. (2018). What you see is what you get? Enhancing methodological transparency in management research. Academy of Management Annals, 12(1), 83-110. https://doi.org/10.5465/annals.2016.0011

Aiken, L. S., West, S. G., \& Reno, R. R. (1991). Multiple regression: Testing and interpreting interactions. Sage Publication.

Ali, Z., \& Bhaskar, S. B. (2016). Basic statistical tools in research and data analysis. Indian Journal of Anaesthesia, 60(9), 662-669. https://doi.org/10.4103/0019-5049.190623

Bass, B. M. (1995). The Revised MLQ 5X. Mind Garden, Palo Alto, CA.

Carlos Do Rego Furtado, L., Da Graça Câmara Batista, M., \& José Ferreira Silva, F. (2011). Leadership and job satisfaction among Azorean hospital nurses: An application of the situational leadership model. Journal of Nursing Management, 19(8), 1047-1057. https://doi.org/10.1111/j.1365-2834.2011.01281.x

Chernick, M. R. (2011). Bootstrap methods: A guide for practitioners and researchers (Vol. 619). John Wiley \& Sons.

Collis, J., \& Hussey, R. (2013). Business research: A practical guide for undergraduate and postgraduate students. Macmillan International Higher Education.

Cooper, D. R., \& Schindler, P. S. (2014). Business Research Methods. The McGraw- Hill Companies.

Cropanzano, R., \& Mitchell, M. S. (2005). Social exchange theory: An interdisciplinary review. Journal of Management, 31(6), 874-900. https://doi.org/10.1177/0149206305279602

Cropanzano, R., Anthony, E. L., Daniels, S. R., \& Hall, A. V. (2017). Social exchange theory: A critical review with theoretical remedies. Academy of Management Annals, 11(1), 479-516. https://doi.org/10.5465/annals.2015.0099

De Lange, A. H., Taris, T. W., Kompier, M. A., Houtman, I. L., \& Bongers, P. M. (2003). "The very best of the millennium": Longitudinal research and the demand-control-(support) model. Journal of Occupational Health Psychology, 8(4), 282-305. https://doi.org/10.1037/1076-8998.8.4.282

DeSimone, J. A., Harms, P. D., \& DeSimone, A. J. (2015). Best practice recommendations for data screening. Journal of Organizational Behavior, 36(2), 171-181. https://doi.org/10.1002/job.1962

Doane, D. P., \& Seward, L. E. (2011). Measuring skewness: A forgotten statistic? Journal of Statistics Education, 19(2), 1-18. https://doi.org/10.1080/10691898.2011.11889611 
Duffield, C. M., Twigg, D. E., Pugh, J. D., Evans, G., Dimitrelis, S., \& Roche, M. A. (2014). The Use of unregulated staff: Time for regulation? Policy, Politics \& Nursing Practice, 15(1-2), 42-48. https://doi.org/10.1177/1527154414529337

Ebrahimi, P., Rezvani Chamanzamin, M., Roohbakhsh, N., \& Shaygan, J. (2017). Transformational and transactional leadership: Which one is more effective in the education of employees' creativity? Considering the moderating role of learning orientation and leader gender. International Journal of Organizational Leadership, 6, 137-156. https://doi.org/10.33844/ijol.2017.60196

Edgar, F., Geare, A., Saunders, D., Beacker, M., \& Faanunu, I. (2017). A transformative service research agenda: A study of workers' well-being. The Service Industries Journal, 37(1), 84-104. https://doi.org/10.1080/02642069.2017.1290797

Ekvall, G., \& Arvonen J. (1994), Leadership profiles, situation and effectiveness. Creativity and Innovation Management, 3(3), 139-161. https://doi.org/10.1111/j.1467-8691.1994.tb00168.x

Farokhzadian, J., Nayeri, N. D., \& Borhani, F. (2018). The long way ahead to achieve an effective patient safety culture: Challenges perceived by nurses. BMC Health Services Research, 18(1), 1-13. https://doi.org/10.1186/s12913-018-3467-1

Fawzy, M., \& Hamed, S. A. (2017). Prevalence of psychological stress, depression and anxiety among medical students in Egypt. Psychiatry Research, 255, 186-194. https://doi.org/10.1016/j.psychres.2017.05.027

Fida, R., Laschinger, H. K. S., \& Leiter, M. P. (2018). The protective role of self-efficacy against workplace incivility and burnout in nursing: A time-lagged study. Health Care Management Review, 43(1), 21-29. https://doi.org/10.1097/HMR.0000000000000126

Firoozabadi, A., Uitdewilligen, S., \& Zijlstra, F. R. (2018). Should you switch off or stay engaged? The consequences of thinking about work on the trajectory of psychological well-being over time. Journal of Occupational Health Psychology, 23(2), 278-288. https://doi.org/10.1037/ocp0000068

Hafiz, A., Ima-Nirwana, S., \& Chin, K. Y. (2018). Comparison of stress levels between physicians working in public and private hospitals in Johor, Malaysia. Journal of Taibah University Medical Sciences, 13(5), 491-495. https://doi.org/10.1016/j.jtumed.2018.01.004

Hair, J. F., Black, W. C., Babin, B. J., \& Anderson, R. E. (2013). Multivariate Data Analysis. Always learning.

Hair, J. F., Ringle, C. M., \& Sarstedt, M. (2011). PLS-SEM: Indeed a silver bullet. Journal of Marketing theory and Practice, 19(2), 139-152. https://doi.org/10.2753/MTP1069-6679190202

Hair, J. F., Black, W. C., Babin, B. J., \& Anderson, R. E. (2010). Multivariate Data Analysis: A Global Perspective (7th ed.). USA: Pearson Prentice Hall, Inc.

Hanusz, Z., \& Tarasińska, J. (2015). Normalization of the Kolmogorov-Smirnov and Shapiro-Wilk tests of normality. Biometrical Letters, 52(2), 85-93. https://doi.org/10.1515/bile-2015-0008

Harmeling, C. M., Moffett, J. W., Arnold, M. J., \& Carlson, B. D. (2017). Toward a theory of customer engagement marketing. Journal of the Academy of Marketing Science, 45(3), 312-335. https://doi.org/10.1007/s11747-016-0509-2

Ho, V. T., \& Astakhova, M. N. (2018). Disentangling passion and engagement: An examination of how and when passionate employees become engaged ones. Human Relations, 71(7), 973-1000. https://doi.org/10.1177/0018726717731505

Hobfoll, S. E., \& Freedy, J. (2017). Conservation of resources: A general stress theory applied to burnout. In Professional burnout (pp. 115-129). Routledge. https://doi.org/10.4324/9781315227979-9

Horton, J., Cameron, A., Devaraj, D., Hanson, R. T., \& Hajkowicz, S. A. (2018). Workplace Safety Futures: The impact of emerging technologies and platforms on work health and safety and workers' compensation over the next 20 years. Canberra, ACT, Australia: CSIRO.

Jyoti, J., \& Bhau, S. (2016). Empirical investigation of moderating and mediating variables in between transformational leadership and related outcomes. International Journal of Educational Management, 30(6), 1123-1149. https://doi.org/10.1108/IJEM-01-2015-0011

Kaiser, H. F. (1974). An index of factor simplicity. Psychometrika, 39(1), 31-36. https://doi.org/10.1007/BF02291575

Kramer, M., Schmalenberg, C., \& Maguire, P. (2010). Nine structures and leadership practices essential for a 
magnetic (healthy) work environment. Nursing Administration Quarterly, 34(1), 4-17. https://doi.org/10.1097/NAQ.0b013e3181c95ef4

Krejcie, R. V., \& Morgan, D. W. (1970). Determining sample size for research activities. Educational and Psychological Measurement, 30(3), 607-610. https://doi.org/10.1177/001316447003000308

MacPhee, M., Chang, L., Lee, D., \& Spiri, W. (2013). Global health care leadership development: Trends to consider. Journal of Healthcare Leadership, 5, 21-29. https://doi.org/10.2147/JHL.S23010

Malhotra, N. K. (Ed.). (2004). Review of marketing research. ME Sharpe. https://doi.org/10.1108/S1548-6435(2004)0000001001

Mowday, R. T., Porter, L. W., \& Steers, R. M. (1982). Employee organization linkages: The psychology of commitment, absenteeism, and turnover. San Diego: Academic Press

Nauman, S., Raja, U., Haq, I. U., \& Bilal, W. (2019). Job demand and employee well-being: A moderated mediation model of emotional intelligence and surface acting. Personnel Review, 48(5), 1150-1168. https://doi.org/10.1108/PR-04-2018-0127

Nielsen, M. B., Skogstad, A., Gjerstad, J., \& Einarsen, S. V. (2019). Are transformational and laissez-faire leadership related to state anxiety among subordinates? A two-wave prospective study of forward and reverse associations. Work \& Stress, 33(2), 137-155. https://doi.org/10.1080/02678373.2018.1528307

Olsen, C., \& St George, D. M. M. (2004). Cross-sectional study design and data analysis. College Entrance Examination Board, 26(3), 2006-2024.

Oppong, F. B., \& Agbedra, S. Y. (2016). Assessing univariate and multivariate normality: A guide for non-statisticians. Mathematical Theory and Modeling, 6(2), 26-33.

Reece, B. L., \& Brandt, R. (1999). Effective human relations in organizations. Houghton Mifflin College Division.

Rippon, D. (2018). The Development of a Theoretical Framework on Work Related Stress in Health and Social Care Professionals who Manage Behaviours that Challenge (Doctoral dissertation, Northumbria University).

Sekaran, U., \& Bougie, R. (2016). Research methods for business: A skill building approach. John Wiley \& Sons.

Saunders, M. N., \& Lewis, P. (2012). Doing research in business \& management: An essential guide to planning your project. Pearson Education.

Sim, D. L., Ansari, M. A., \& Jantan, M. (2004). Delegation styles and leadership perceptions: A comparison of Malaysian and American managers. Academy of Management Meeting, New Orleans, LA.

Um, K., \& Yoo, T. S. (2018). Effects of Collective Leadership on Follower's Work Engagement: Examining the role of Psychological Empowerment and Self-efficacy. The Journal of Korea Contents Association, 18(8), 415-433.

Yamaguchi, A., Kim, M. S., Oshio, A., \& Akutsu, S. (2017). The role of anger regulation on perceived stress status and physical health. Personality and Individual Differences, 116, 240-245. https://doi.org/10.1016/j.paid.2017.03.053

Yuk1, G. (2002). Leadership in Organizations (5th ed.). Prentice Hall, New Jersey, NY.

\section{Copyrights}

Copyright for this article is retained by the author(s), with first publication rights granted to the journal.

This is an open-access article distributed under the terms and conditions of the Creative Commons Attribution license (http://creativecommons.org/licenses/by/4.0/). 